\title{
Laparoscopic Sleeve Gastrectomy Improves Excessive Daytime Sleepiness and Sleep Quality 6 Months Following Surgery: A Prospective Cohort Study
}

\author{
Evren Dilektasli · Asli Gorek Dilektasli
}

Received: January 10, 2016 / Published online: March 26, 2016

(C) The Author(s) 2016. This article is published with open access at Springerlink.com

\begin{abstract}
Introduction: Obstructive sleep apnea (OSA) is one of the most important co-morbid conditions related with morbid obesity. Bariatric procedures are associated with significant improvement in OSA. The aim of the current study was to evaluate the effect of bariatric surgery on daytime sleepiness and quality of sleep in patients that had undergone laparoscopic sleeve gastrectomy.

Methods: Fifty-nine patients were prospectively enrolled in the study. Pre-operative and post-operative (6 months) demographics, medical history, weight, and height of the patients were recorded, and patients were asked to complete Pittsburg Sleep Quality Index (PSQI) and Epworth Sleepiness Scale
\end{abstract}

Enhanced content To view enhanced content for this article go to http://www.medengine.com/Redeem/3A84 F06018B1FF80.

E. Dilektasli $(\bowtie)$

Department of Surgery, Yuksek Ihtisas Training and Research Hospital, Bursa, Turkey

e-mail: edilektasli@gmail.com

A. G. Dilektasli

Department of Pulmonary Medicine, Uludag

University Faculty of Medicine, Bursa, Turkey
(ESS) questionnaires. OSA screenings were performed using the STOP-Bang questionnaire.

Results: The mean age of the patients was $37.1 \pm 1.2$ years and $76 \%$ were female. Pre-operative and post-operative median (range) BMIs were $47 \mathrm{~kg} / \mathrm{m}^{2}\left(39-67 \mathrm{~kg} / \mathrm{m}^{2}\right)$ and $35 \mathrm{~kg} / \mathrm{m}^{2} \quad\left(25-44 \mathrm{~kg} / \mathrm{m}^{2}\right), \quad$ respectively $(P<0.001)$. The mean \pm standard deviation excess weight loss was $51.6 \pm 13.2 \%$. In univariate analysis, total PSQI, STOP-Bang, and ESS scores were found to significantly improve 6 months after surgery (all $P<0.001$ ). Multivariate mixed-model analysis showed a high correlation between the decrease in BMI and all key predictors. Mixed-model analysis revealed that every $1 \mathrm{~kg} / \mathrm{m}^{2}$ decrease in BMI was associated with a 0.32, 0.13, and 0.26 improvements in PSQI, STOP-Bang, and ESS scores, respectively (all $P<0.001$ ).

Conclusion: Laparoscopic sleeve gastrectomy is associated with rapid weight loss and improvements in sleep quality, daytime sleepiness, and the risk of OSA 6 months after surgery.

Keywords: Bariatric surgery; Epworth Sleepiness Scale; Laparoscopic sleeve 
gastrectomy; Morbid obesity; Obstructive sleep apnea; Pittsburg Sleep Quality Index; Sleep quality; Sleeve gastrectomy; STOP-Bang; Surgery

\section{INTRODUCTION}

Obesity and the co-morbidities related to obesity are increasing. In the United States, $69 \%$ of the general population who are 20 years of age or older are overweight or obese according to the Centers for Disease Control and Prevention [1]. One of the well-known co-morbid factors related to obesity is obstructive sleep apnea (OSA). OSA is a disorder that is characterized by recurrent episodes of upper airway collapse causing apnea and hypopnea during sleep [2]. It has been shown that the prevalence of OSA varies from $60 \%$ to $83 \%$ in the obese population with a body mass index (BMI) of $\geq 35 \mathrm{~kg} / \mathrm{m}^{2}$ [3].

Conversely, OSA has been shown to be a stand-alone factor that increases the risk of obesity [4, 5]. After bariatric surgery, it has been shown that the severity and symptoms of OSA decrease or sometimes even completely resolve with successful weight loss [6]. Overnight polysomnography (PSG) is the gold standard for the diagnosis of OSA $[7,8]$. However, not all patients who are morbidly obese are routinely tested and diagnosed for OSA by a PSG test. Clinicians often use different screening tools such as the STOP-Bang and ESS questionnaires in the pre-operative setting $[9,10]$.

In early months after sleeve gastrectomy, especially in first 6 months, average weight loss is about $50 \%$ of the excess body weight [11]. There are no adequate data on the possible improvement of sleep apnea, daytime sleepiness, and sleep quality in 6-month post-operative period in which this rapid weight loss is achieved. The primary outcome of this study was to evaluate the quality of sleep, daytime sleepiness, and risk of OSA in patients scheduled for obesity surgery. The secondary outcome was to determine the effects of weight loss in the 6-month post-operative period on the possible improvements in OSA, daytime sleepiness, and the quality of sleep.

\section{METHODS}

The institutional ethical committee of the Sevket Yilmaz Training and Research Hospital approved the study protocol and the patient consent forms the study. The study was conducted between November 2013 and July 2014, and data were collected prospectively between the study dates. All patients with a diagnosis of morbid obesity (BMI $\geq 35 \mathrm{~kg} / \mathrm{m}^{2}$ ) who underwent a laparoscopic sleeve gastrectomy operation were consecutively enrolled in the study. Patients who declined to participate in the study or who were lost during follow-up were excluded. In the pre-operative interventions, PSG was not the routine procedure unless it is indicated or strictly advised during the pre-operative pulmonology department visit. OSA screenings were performed by STOP-Bang questionnaire. The following variables were collected pre-operatively and 6 months post-operatively: age, gender, past medical history, weight, height, and BMI. Pre-operatively and 6 months post-operatively, patients were asked to fill out the Pittsburg Sleep Quality Index (PSQI), STOP-Bang, and Epworth Sleepiness Scale (ESS) questionnaires.

\section{PSQI}

The PSQI is a validated self-report questionnaire to measure the quality and the patterns of sleep in adults, its advantage being the ease in its clinical usage [12]. It includes 19 items that 
generate seven-component scores: subjective sleep quality, sleep latency, sleep duration, habitual sleep efficiency, sleep disturbances, use of sleep medication, and daytime dysfunction over the last month. The questions have answers based on a $0-3$ scale, where 0 reflects good and 3 reflects poor quality of sleep, for those different sleep problem areas. The Turkish version of the PSQI was validated by Agargun et al. [13].

\section{STOP-Bang}

The STOP-Bang questionnaire is a tool that has been shown to be effective in predicting the risk of OSA for patients in the pre-operative period [14]. According to the questionnaire, the presence of loud snoring, tiredness, observed apnea, high blood pressure, BMI over $35 \mathrm{~kg} / \mathrm{m}^{2}$, age over 50 years, neck circumference over $46 \mathrm{~cm}$, and male gender each score 1 point. The total score is from a minimum of 0 to maximum 8. A total score of $\geq 4$ has a high sensitivity in predicting severe OSA pre-operatively for patients undergoing surgery who are obese or morbidly obese [15]. Studies which focused on the effect of a high STOP-Bang score on the surgical outcomes for patients who were not using continuous positive airway pressure (CPAP) devices and who were not diagnosed with PSG found that patients with a STOP-Bang score of $\geq 3$ have a higher risk of post-operative complications and an increased length of stay in hospital $[16,17]$. The Turkish version of the STOP-Bang was validated by Acar et al. [18].

\section{ESS}

The ESS is a validated self-reported eight-item questionnaire used to measure self-reported sleep propensity [19]. The questions are based on the patient's probability of falling asleep with a scale of increasing probability from 0 to 3 for 8 different situations during their daily life. A total ESS score of $<10$ is considered to be within normal range while scores of $\geq 10$ indicates excessive daytime sleepiness and scores of between 16 and 24 indicate a high level of daytime sleepiness [19]. Most people can answer the ESS, without assistance, in 2 or $3 \mathrm{~min}$. The reliability and validity of the ESS in Turkish language was previously shown by Izci et al. [20].

\section{Statistical Analysis}

The data were analyzed for normal distribution of continuous variables using histograms and the Shapiro-Wilk test. The normally distributed continuous variables were reported as mean \pm standard deviation (SD), while the non-normally distributed data were reported as medians (range). Categorical variables were reported as frequencies and percentages. To examine the differences between pre-operative and 6-month post-operative results, categorical covariates were analyzed using McNemar's test, while the continuous covariates were analyzed based on paired samples $t$ test and Wilcoxon signed-rank tests. In multivariate analysis, a linear mixed-model repeated-analysis design was used to estimate the association between the change in BMI in pre-operative and post-operative periods with the change in PSQI, STOP-Bang, and ESS scores. Unless otherwise indicated, a 5\% type-I error level was used to refer statistical significance. All statistical analysis was performed using SPSS for Mac version 20.0 (SPSS Inc., Chicago, IL, USA).

\section{RESULTS}

During the study period, a sleeve gastrectomy operation was performed in 65 patients with a 
Table 1 Patient baseline characteristics

\begin{tabular}{ll}
\hline Characteristics & Value \\
\hline$N$ & 59 \\
Mean ( \pm standard deviation) age, years & $37.1 \pm 1.2$ \\
Female, $n(\%)$ & $45(76.3)$ \\
Pulmonary history, $n(\%)$ & \\
Obstructive sleep apnea & $5(8.5)$ \\
Tobacco use & $27(45.8)$ \\
\hline
\end{tabular}

diagnosis of morbid obesity. After four patients declined to participate in the study period and two patients were lost in the follow-up, 59 patients were included in the study. The mean age of patients was 37.1 years and the majority were female (76.3\%; Table 1$)$.

Only five patients $[8.5 \%$, 95\% confidence interval (CI): 3.7-18.3\%] had a documented history of OSA and they started using a CPAP device for $18 \pm 14.6$ months before their operation date. Two of the patients with OSA were newly diagnosed in the routine pre-operative evaluation by the pulmonologist. The minimum and the maximum apnea hypopnea index for those five patients were 18 and 95, respectively. With the rapid weight loss that was achieved in the early months after surgery, all of these patients gave up using their CPAP devices with an improvement in their sleep qualities and a decrease in their daytime sleepiness. The mean excess weight loss (EWL) of these five patients was $55.7 \pm 10.5 \%$, which was similar with overall EWL. Since CPAP therapy is a possible confounder that might have affected the primary study outcome, seven patients on CPAP therapy were further excluded from the analysis, and univariate and multivariate analysis were performed with the remaining 52 patients.

In 6-month post-operative period, the median weight had decreased from 127 to $90 \mathrm{~kg}$, and the median BMI decreased from 47 to $35 \mathrm{~kg} / \mathrm{m}^{2}$ (Fig. 2a). The calculated percentage BMI loss was $28.2 \pm 6.6 \%$ and the percentage EWL was $51.6 \pm 13.2 \%$ (Table 2).

In the pre-operative period, $22 / 52(42.3 \%$, 95\% CI 29.9-55.8\%) patients had a score of $\geq 10$ when the results of the ESS were considered, which represents excessive daytime sleepiness, while only one patient $(1.9 \%, 95 \%$ CI $0.3-10.1 \%$ ) had a score of $\geq 10$ in 6 -month

Table 2 Pre-operative and post-operative changes in weight, BMI, and co-morbidities $(n=52)$

\begin{tabular}{lclr}
\hline Characteristics & Pre-operative & Post-operative (6 months) & P value \\
\hline Weight, median (range) & $127(98-178)$ & $90(63-138)$ & $<0.001^{\mathrm{a}}$ \\
BMI, median (range) & $47(39-67)$ & $35(25-44)$ & $<0.001^{\mathrm{a}}$ \\
Diabetes mellitus, $n(\%)$ & $9(17.3)$ & $4(7.7)$ & $0.063^{\mathrm{b}}$ \\
Hypertension, $n$ (\%) & $12(23.1)$ & $5(9.6)$ & $0.016^{\mathrm{b}}$ \\
Musculoskeletal complaints, $n(\%)$ & $31(59.6)$ & $12(23.1)$ & $<0.001^{\mathrm{b}}$ \\
Percentage BMI loss, mean \pm SD & & $28.2 \pm 6.6$ & \\
Percentage EBMI loss, mean \pm SD & & $59.3 \pm 13.3$ & \\
Percentage EWL, mean \pm SD & & $51.6 \pm 13.2$ & \\
\hline
\end{tabular}

$B M I$ body mass index, EBMI excess body mass index, $E W L$ excess weight loss, $S D$ standard deviation

a Wilcoxon signed-rank test

b McNemar's test 


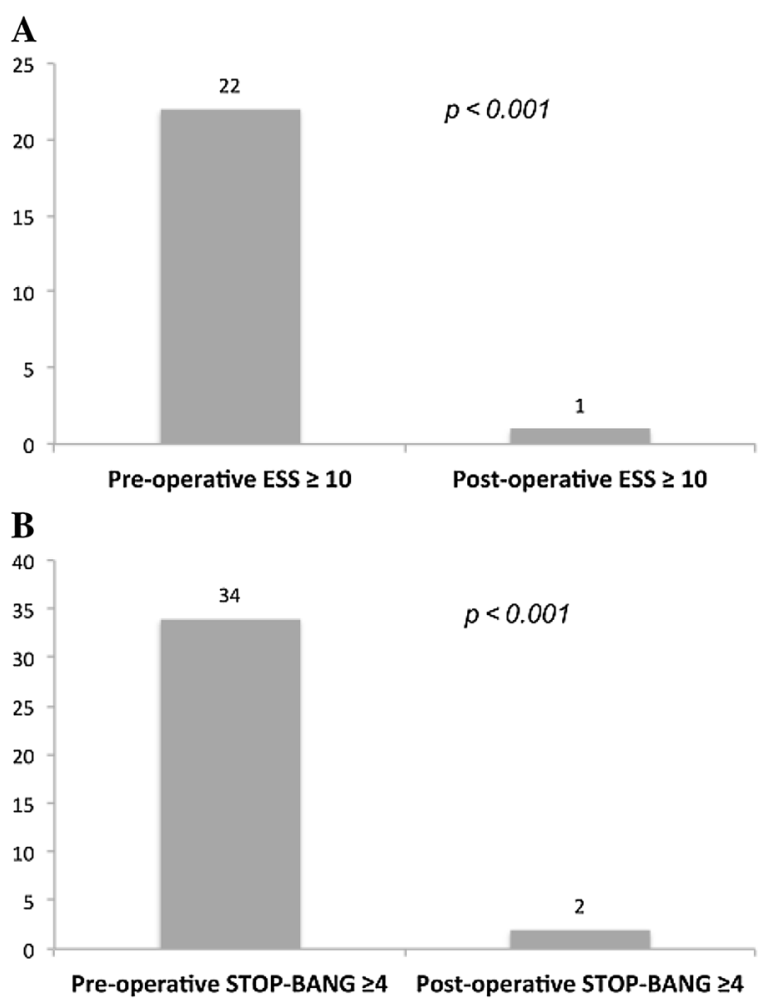

Fig. 1 The change in OSA risk according to pre-operative and post-operative ESS and STOP-Bang scores. a ESS score $\geq 10$ representing excessive daytime sleepiness. b STOP-Bang score $\geq 4$ representing high risk for OSA. ESS Epworth Sleepiness Scale, OSA obstructive sleep apnea

post-operative period $(P<0.001 ; \quad$ Fig. 1a). Similarly according to STOP-Bang, 34/52 (65.4\%, 95\% CI $51.8-76.9 \%)$ pre-operative patients had a score of $\geq 4$ and were considered as a high risk for OSA. On the other hand, only $2 / 59 \quad(3.9 \%, \quad 95 \%$ CI: $1.1-13.0 \%)$ patients had a score of $\geq 4$ 6 months after the surgery $(P<0.001$; Fig. $1 b)$.

A significant improvement in all of the PSQI subscale scores at 6 months following the operation was observed, when compared with the pre-surgery scores (all $P<0.001$ ). The total PSQI score (range) improved from 9.0 (2.0-17.0) to $3.0(1.0-9.0)$ by the 6-month post-operative period $(P<0.001$; Table 3; Fig. $2 b)$.

Compared to the pre-operative evaluation, the STOP-Bang total score significantly decreased from $3.9 \pm 1.2$ to $1.8 \pm 1.0$ in the 6 months following the sleeve gastrectomy operation $(P<0.001$; Fig. $2 c)$. Similarly, the mean pre-operative ESS score of $9.0 \pm 4.6$ decreased to $3.5 \pm 2.2$ at the 6-month post-operative evaluation $(P<0.001$; Fig. 2 d).

To evaluate the effects of the change in BMI on the PSQI, STOP-Bang, and ESS, a multivariate mixed-model analysis was performed separately for each key predictor. After adjustment for age and gender, a high association between the decrease in BMI and all key predictors was demonstrated. Mixed-model analysis revealed that every $1 \mathrm{~kg} / \mathrm{m}^{2}$ decrease in BMI was associated with a 0.32, 0.13, and 0.26 improvement in PSQI, STOP-Bang, and ESS scores, respectively (all $P<0.001$; Table 4 ).

\section{DISCUSSION}

The results of the current study demonstrate that sleep quality is significantly reduced and that excessive daytime somnolence is very common in patients who are morbidly obese who are referred for bariatric surgery. Moreover, the results show a significant improvement in STOP-Bang score-a validated tool of OSA screening in obese population [12]—in addition to excessive daytime sleepiness and quality of sleep assessments 6 months after laparoscopic sleeve gastrectomy.

Bariatric surgery is widely accepted as one of the primary treatments for patients who are morbidly obese. Sleeve gastrectomy, which has gained popularity in previous decade, was shown to be a successful method for achieving sustained weight loss and decreasing the morbidity after surgery. The loss of the excess weight after surgery is known to be higher in the early post-operative phases, mostly due to the operative stress, decreased hunger, and increased satiety in early operative periods [21, 
Table 3 Comparison of ESS, PSQI, and STOP-Bang in pre-operative and post-operative patients $(n=52)$

\begin{tabular}{|c|c|c|c|}
\hline Scales & Pre-operative & Post-operative (6 months) & $P$ value \\
\hline \multicolumn{4}{|l|}{ PSQI, median (range) } \\
\hline Sleep duration & $1.0(0.0-3.0)$ & $0.0(0.0-3.0)$ & $<0.001^{\mathrm{a}}$ \\
\hline Sleep disturbances & $2.0(1.0-3.0)$ & $1.0(0.0-2.0)$ & \\
\hline Sleep latency & $2.0(0.0-3.0)$ & $1.0(0.0-3.0)$ & \\
\hline Daytime dysfunction & $1.0(0.0-3.0)$ & $1.0(0.0-2.0)$ & \\
\hline Habitual sleep efficiency & $1.0(0.0-3.0)$ & $0.0(0.0-3.0)$ & \\
\hline Subjective sleep quality & $1.0(0.0-3.0)$ & $0.0(0.0-2.0)$ & \\
\hline Use of sleep medications & $1.0(0.0-3.0)$ & $0.0(0.0-2.0)$ & \\
\hline Total & $9.0(2.0-17.0)$ & $3.0(1.0-9.0)$ & $<0.001^{\mathrm{a}}$ \\
\hline STOP-Bang, mean \pm SD & $3.9 \pm 1.2$ & $1.8 \pm 1.0$ & $<0.001^{\mathrm{b}}$ \\
\hline ESS, mean $\pm S D$ & $9.0 \pm 4.6$ & $3.5 \pm 2.2$ & $<0.001^{\mathrm{b}}$ \\
\hline
\end{tabular}

ESS Epworth Sleepiness Scale, PSQI Pittsburg Sleep Quality Index, SD Standard deviation

${ }^{a}$ Wilcoxon signed-rank test

${ }^{\mathrm{b}}$ Paired samples $t$ test

22]. These changes have been shown to be related with alterations in gut hormones such as ghrelin, peptide YY, and glucagon-like peptide 1 [23-25]. In the current literature, with different surgical operations or with non-surgical endoscopic approaches, the percentage EWL 6 months after surgery has been found to be between $33.6 \%$ and $52.6 \%$ [26, 27]. In the study by Nocca et al. [28], the percentage EWL was found to be $48.9 \%$ in 6 -month post-operative follow-up period, specifically after sleeve gastrectomy. In accordance with previous reports, the current authors found the percentage EWL and excess BMI loss to be $51.6 \%$ and $59.3 \%$, respectively, 6 months after sleeve gastrectomy (Table 2).

Laparoscopic sleeve gastrectomy has also been shown to be an excellent operation for the resolution of co-morbidities [29]. In some series, some co-morbidities like diabetes mellitus and OSA are completely resolved, and many others (such as hypertension, musculoskeletal complaints, and dyslipidemia) are dramatically improved 12 or 24 months after surgery $[25,26]$. In this cohort study, the authors found that nearly $60 \%$ of documented co-morbidities resolved just 6 months after the surgery in patients that had undergone sleeve gastrectomy (Table 2).

It is well known that obesity and OSA have a strong relationship [30, 31]. Studies that have aimed to explain the mechanisms related to obesity and OSA focused on the role of fat around upper airways and pharynx [32, 33], as well as the hormonal changes in ghrelin, leptin, adiponectin, and even in growth hormone [34-37]. Studies have shown that short sleep duration is associated with significant weight gain, and increased BMI was associated with reduced sleep efficiency and change in sleep architecture [38]. The vast majority of patients that undergo bariatric procedures have different grades of OSA. Unfortunately, due to the challenges in the diagnosis of OSA, most of 
A

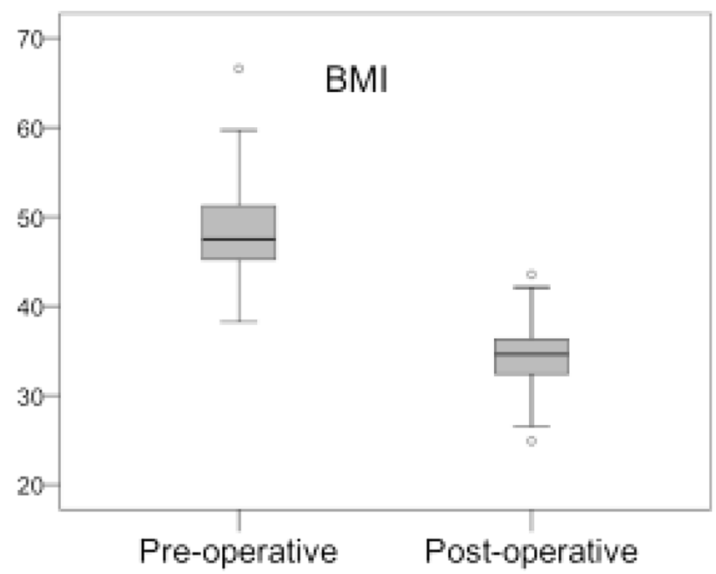

C

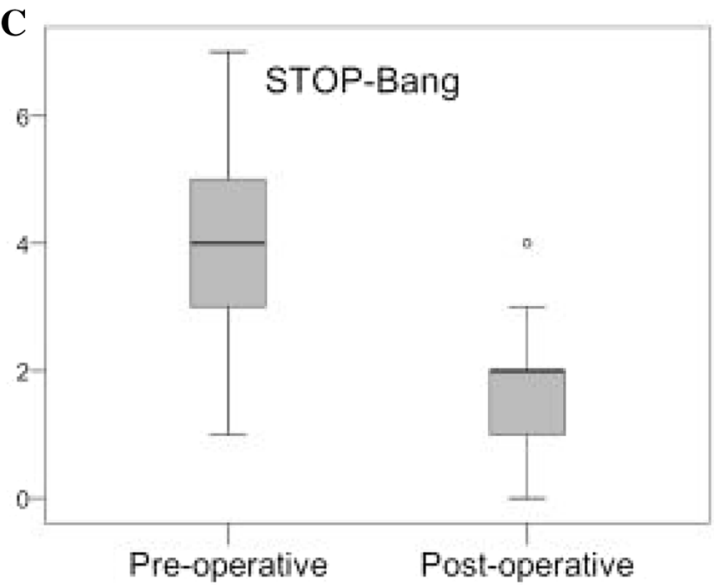

B

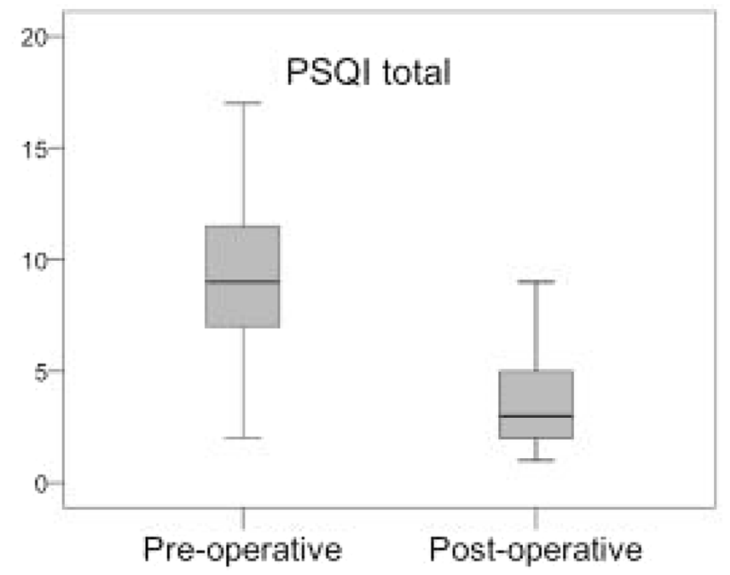

D

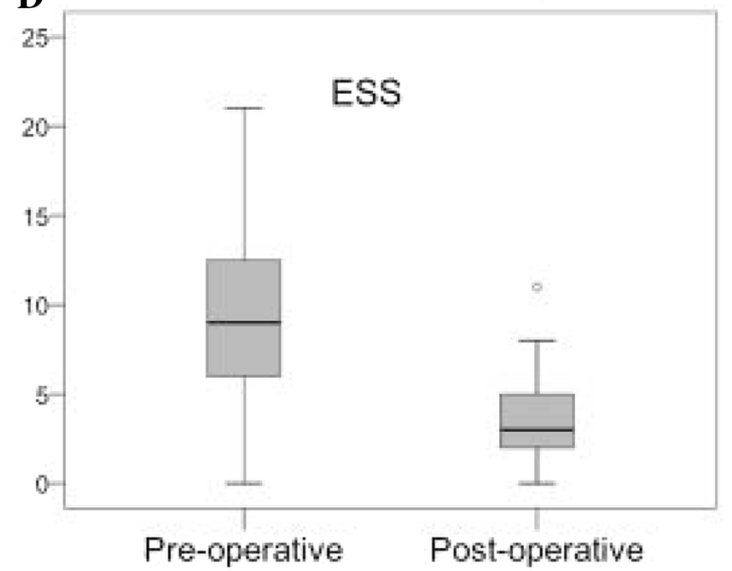

Fig. 2 Distribution of pre-operative and post-operative a BMI, b PSQI, c STOP-Bang, and d ESS. $P$ values $<0.001$. BMI body mass index, ESS Epworth Sleepiness Scale, PSQI Pittsburg Sleep Quality Index

them remain undiagnosed [39]. Overnight PSG is the gold standard for the diagnosis of OSA. However, it is expensive, time-consuming, and not available in every institution. For that reason, it is recommended to better identify high-risk patients, i.e., those most likely to have OSA, by easier and cheaper screening tools such as STOP-Bang and ESS in the pre-operative setting [40].

In a previous study, Holty et al. [41] described significant reductions in mean ESS scores 24 months after bariatric surgery; however, in that study the operation of choice was vertical gastrectomy and Roux-en-Y gastric bypass. In the current study, the authors found that the 6-month post-operative mean ESS scores after sleeve gastrectomy were significantly reduced from $9.0 \pm 4.6$ to $3.5 \pm 2.2(P<0.001)$. According to the ESS scores, 22 patients had excessive daytime sleepiness pre-operatively, while only 1 patient had excessive daytime sleepiness 6 months after the operation. This finding shows the effectiveness of surgical weight loss on daytime sleepiness with the effective improvement in excessive daytime sleepiness in patients who are morbidly obese.

The STOP-Bang questionnaire is another screening tool that has been shown to be valid in surgical patients who are morbidly obese. In 
Table 4 Mixed-model analysis of PSQI total, ESS, and STOP-Bang for 6-month BMI change after sleeve gastrectomy $(n=52)$

\begin{tabular}{lllr}
\hline Models & Parameter estimates & Standard error & P value \\
\hline Model 1 (PSQI total) & & & \\
Intercept & -4.10 & 1.85 & 0.029 \\
Age & -0.07 & 0.03 & 0.031 \\
Gender (female) & -0.52 & 0.82 & 0.528 \\
Decrease in BMI $\left(\mathrm{kg} / \mathrm{m}^{2}\right)$ & -0.32 & 0.04 & $<0.001$ \\
Model 2 (STOP-Bang) & & & \\
Intercept & -3.34 & 0.63 & $<0.001$ \\
Age & 0.04 & 0.11 & $<0.001$ \\
Gender (female) & -0.55 & 0.28 & 0.055 \\
Decrease in BMI $\left(\mathrm{kg} / \mathrm{m}^{2}\right)$ & -0.13 & 0.01 & $<0.001$ \\
Model 3 (ESS) & & & \\
Intercept & -5.04 & 2.48 & 0.045 \\
Age & 0.06 & 0.04 & 0.155 \\
Gender (female) & -1.92 & 1.10 & 0.085 \\
Decrease in BMI $\left(\mathrm{kg} / \mathrm{m}^{2}\right)$ & -0.26 & 0.05 & $<0.001$ \\
\hline
\end{tabular}

BMI body mass index, ESS Epworth Sleepiness Scale, PSQI Pittsburg Sleep Quality Index

patients who are morbidly obese, it was shown that a STOP-Bang score of $\geq 4$ has a sensitivity of $90 \%$ for predicting severe OSA [15]. In this study, the authors have shown that the pre-operative mean STOP-Bang score decreases from $3.9 \pm 1.2$ to $1.8 \pm 1.0$ just 6 months after sleeve gastrectomy $(P<0.001)$. The finding that there is a significant reduction in the number of patients with a total STOP-Bang score of $\geq 4$ from 34 pre-operatively to 2 in the 6-month post-operative period suggests the effectiveness of sleeve gastrectomy in the improvement of the risk for OSA, even in the relatively early period following surgery. The authors further suggest that, in the follow-up period after operations for morbid obesity, this simple screening tool could easily be used in clinical practice and provides valuable information about OSA.

Toor and colleagues [42] have shown that candidates for bariatric surgery have a shorter total sleep duration, which interfered with poor sleep quality in their study including 45 patients who were morbidly obese and their non-obese controls. Moreover, they found that weight-loss surgery resulted in a highly significant improvement in sleep quality with a significant improvement in PSQI scores. However, their study included a heterogeneous group with regard to the selected surgical procedure (Roux-en-Y gastric bypass in 32 patients and sleeve gastrectomy in 13 patients), resulting in being able to include a relatively smaller patient population for sleeve 
gastrectomy. In the present study, in a relatively larger study population, the authors have shown by PSQI scores that sleeve gastrectomy significantly improves sleep quality (Table 3 ).

There are several limitations of the current study. First of all, the most important limitation is the lack of PSG. The improvement of OSA could only be demonstrated with overnight recordings performed using portable limited channel recorders (respiratory polygraphy) or full PSG. Since it was not easily accessible, the authors were unable to confirm OSA diagnosis by PSG in the current study. By performing the questionnaires, the authors were only able to evaluate 'the risk of OSA'. Secondly, other possible disorders that may adversely affect sleep quality and cause sleep pattern disturbance, such as psychiatric disorders, were not captured in this study [43]. After surgical weight loss, sleep quality may also be positively affected by an improvement in mood and other psychological factors. Unfortunately, in this study the authors did not perform such psychiatric measures. Bariatric surgery has been shown to be associated with an improvement in quality of life and overall psychological status on its own [44, 45]. Moreover, prostatic hyperplasia [46], gastritis [47], gastro-esophageal reflux disease [48], and numerous other co-morbidities, along with the medications used, may adversely affect sleep quality and may also have a possible impact on sleep disturbances. The status of physical activity, behavior modification, and many other confounders are also associated with sleep disturbances $[49,50]$. These disorders and confounders were not captured for this study and is another major limitation that should be noted. Further studies in bariatric surgery are needed, with larger study populations and greater consideration to the co-morbid conditions that may interact with sleep disorders and obesity.

The strength of the current study is that the findings are based on a single type of surgery that was performed by a bariatric surgery team which performs over 100 bariatric surgery procedures per year. The use of structurally and linguistically validated questionnaires is another power of the study. Of note, since these questionnaires are long and may be hard to complete for some patients, all were completed under the guidance of an experienced clinician.

\section{CONCLUSIONS}

Laparoscopic sleeve gastrectomy is a stand-alone surgery for achieving adequate weight loss. The decrease in BMI is associated with the resolution of co-morbidities that are related to obesity. The current study shows that, even 6 months following the sleeve gastrectomy operation, sleep quality and excessive daytime sleepiness are improving. When OSA and related co-morbidities are considered, this finding is one of the possible reasons for the noted success of this procedure. Moreover, STOP-Bang is a promising tool to screen for OSA in the post-operative period, as well as during the pre-operative risk assessment.

\section{ACKNOWLEDGMENTS}

No funding or sponsorship was received for this study or publication of this article. The article processing charges and open access fee were funded by the authors. The authors would like to thank to Gurcan Kisakol MD and Guven Ozkaya MD for their valuable comments and suggestions. All named authors meet the 
International Committee of Medical Journal Editors (ICMJE) criteria for authorship for this manuscript, take responsibility for the integrity of the work as a whole, and have given final approval to the version to be published.

Disclosures. Evren Dilektasli and Asli Gorek Dilektasli declare no conflict of interest.

Compliance with Ethics Guidelines. All procedures followed were in accordance with the ethical standards of the responsible committee on human experimentation (institutional and national) and with the Helsinki Declaration of 1964, as revised in 2013. Informed consent was obtained from all patients for being included in the study.

Open Access. This article is distributed under the terms of the Creative Commons Attribution-NonCommercial 4.0 International License (http://creativecommons.org/licenses/ by-nc/4.0/), which permits any noncommercial use, distribution, and reproduction in any medium, provided you give appropriate credit to the original author(s) and the source, provide a link to the Creative Commons license, and indicate if changes were made.

\section{REFERENCES}

1. National Center for Health Statistics. Health, United States, 2014: with special feature on adults aged 55-64. Hyattsville, MD. 2015.

2. Jordan AS, McSharry DG, Malhotra A. Adult obstructive sleep apnoea. Lancet. 2014;383:736-47.

3. Ashrafian H, le Roux CW, Rowland SP, Ali M, Cummin AR, Darzi A, Athanasiou T. Metabolic surgery and obstructive sleep apnoea: the protective effects of bariatric procedures. Thorax. 2012;67:442-9.

4. Gangwisch JE, Malaspina D, Boden-Albala B, Heymsfield SB. Inadequate sleep as a risk factor for obesity: analyses of the NHANES I. Sleep. 2005;28:1289-96.

5. Hasler G, Buysse DJ, Klaghofer R, Gamma A, Ajdacic V, Eich D, Rossler W, Angst J. The association between short sleep duration and obesity in young adults: a 13-year prospective study. Sleep. 2004;27:661-6.

6. Fritscher LG, Mottin CC, Canani S, Chatkin JM. Obesity and obstructive sleep apnea-hypopnea syndrome: the impact of bariatric surgery. Obes Surg. 2007;17:95-9.

7. Shechter A, St-Onge MP, Kuna ST, Zammit G, RoyChoudhury A, Newman AB, Millman RP, Reboussin DM, Wadden TA, Jakicic JM, Pi-Sunyer FX, Wing RR, Foster GD, Sleep ARGotLARG. Sleep architecture following a weight loss intervention in overweight and obese patients with obstructive sleep apnea and type 2 diabetes: relationship to apnea-hypopnea index. J Clin Sleep Med. 2014;10:1205-11.

8. Qaseem A, Holty JE, Owens DK, Dallas P, Starkey M, Shekelle P, Clinical Guidelines Committee of the American College of P. Management of obstructive sleep apnea in adults: a clinical practice guideline from the American College of Physicians. Ann Intern Med. 2013;159:471-83.

9. Del Genio G, Limongelli P, Del Genio F, Motta G, Docimo L, Testa D. Sleeve gastrectomy improves obstructive sleep apnea syndrome (OSAS): 5 year longitudinal study. Surg Obes Relat Dis. 2016;12:70-4.

10. Oliveira MG, Treptow EC, Fukuda C, Nery LE, Valadares RM, Tufik S, Bittencourt L, Togeiro SM. Diagnostic accuracy of home-based monitoring system in morbidly obese patients with high risk for sleep apnea. Obes Surg. 2015;25:845-51.

11. Albeladi B, Bourbao-Tournois C, Huten N. Shortand midterm results between laparoscopic Roux-en-Y gastric bypass and laparoscopic sleeve gastrectomy for the treatment of morbid obesity. J Obes. 2013;2013:934653.

12. Buysse DJ, Reynolds CF 3rd, Monk TH, Berman SR, Kupfer DJ. The Pittsburgh sleep quality index: a new instrument for psychiatric practice and research. Psychiatry Res. 1989;28:193-213.

13. Agargun MYKH, Anlar O. Pittsburgh Uyku Kalitesi İndeksinin geçerliği ve güvenirliği. Türk Psikiyatri Derg. 1996;7:107-15.

14. Chung F, Subramanyam R, Liao P, Sasaki E, Shapiro C, Sun Y. High STOP-Bang score indicates a high probability of obstructive sleep apnoea. $\mathrm{Br} J$ Anaesth. 2012;108:768-75. 
15. Chung F, Yang Y, Liao P. Predictive performance of the STOP-Bang score for identifying obstructive sleep apnea in obese patients. Obes Surg. 2013;23:2050-7.

16. Proczko MA, Stepaniak PS, De Quelerij M, Van der Lely FH, Smulders JF, Kaska L, Soliman Hamad MA. STOP-Bang and the effect on patient outcome and length of hospital stay when patients are not using continuous positive airway pressure. J Anesth. 2014;28:891-7.

17. Xara D, Mendonca J, Pereira H, Santos A, Abelha FJ. Adverse respiratory events after general anesthesia in patients at high risk of obstructive sleep apnea syndrome. Braz J Anesthesiol. 2015;65:359-66.

18. Acar HV, Kaya A, Yucel F, Erdem M, Gunal SE, Ozgen F, Dikmen B. Validation of the STOP-bang questionnaire: an obstructive sleep apnoea screening tool in turkish population. Turk J Anaesth Reanim. 2013;41(4):115-20.

19. Johns MW. A new method for measuring daytime sleepiness: the Epworth sleepiness scale. Sleep. 1991;14:540-5.

20. Izci B, Ardic S, Firat H, Sahin A, Altinors M, Karacan I. Reliability and validity studies of the Turkish version of the Epworth Sleepiness Scale. Sleep Breath. 2008;12:161-8.

21. Dixon AF, Dixon JB, O'Brien PE. Laparoscopic adjustable gastric banding induces prolonged satiety: a randomized blind crossover study. J Clin Endocrinol Metab. 2005;90:813-9.

22. Poirier P, Cornier MA, Mazzone T, Stiles S, Cummings S, Klein S, McCullough PA, Ren Fielding C, Franklin BA, American Heart Association Obesity Committee of the Council on Nutrition PA and Metabolism. Bariatric surgery and cardiovascular risk factors: a scientific statement from the American Heart Association. Circulation. 2011;123:1683-701.

23. Vincent RP, le Roux CW. Changes in gut hormones after bariatric surgery. Clin Endocrinol (Oxf). 2008;69:173-9.

24. Anderson B, Switzer NJ, Almamar A, Shi X, Birch DW, Karmali S. The impact of laparoscopic sleeve gastrectomy on plasma ghrelin levels: a systematic review. Obes Surg. 2013;23:1476-80.

25. Papailiou J, Albanopoulos K, Toutouzas KG, Tsigris C, Nikiteas N, Zografos G. Morbid obesity and sleeve gastrectomy: how does it work? Obes Surg. 2010;20:1448-55.

26. Albanopoulos K, Tsamis D, Natoudi M, Alevizos L, Zografos G, Leandros E. The impact of laparoscopic sleeve gastrectomy on weight loss and obesity-associated comorbidities: the results of 3 years of follow-up. Surg Endosc. 2016;30(2): 699-705.

27. Genco A, Cipriano M, Materia A, Bacci V, Maselli R, Musmeci L, Lorenzo M, Basso N. Laparoscopic sleeve gastrectomy versus intragastric balloon: a case-control study. Surg Endosc. 2009;23: 1849-53.

28. Nocca D, Krawczykowsky D, Bomans B, Picot MC, Blanc PM, de Seguin de Hons C, Millat B, Gagner M, Monnier L, Fabre JM. A prospective multicenter study of 163 sleeve gastrectomies: results at 1 and 2 years. Obes Surg. 2008;18:560-5.

29. Svane MS, Madsbad S. Bariatric surgery-effects on obesity and related co-morbidities. Curr Diabetes Rev. 2014;10:208-14.

30. Romero-Corral A, Caples SM, Lopez-Jimenez F, Somers VK. Interactions between obesity and obstructive sleep apnea: implications for treatment. Chest. 2010;137:711-9.

31. Drager LF, Togeiro SM, Polotsky VY, Lorenzi-Filho G. Obstructive sleep apnea: a cardiometabolic risk in obesity and the metabolic syndrome. J Am Coll Cardiol. 2013;62:569-76.

32. Liu KH, Chu WC, To KW, Ko FW, Tong MW, Chan JW, Hui DS. Sonographic measurement of lateral parapharyngeal wall thickness in patients with obstructive sleep apnea. Sleep. 2007;30:1503-8.

33. Horner RL, Mohiaddin RH, Lowell DG, Shea SA, Burman ED, Longmore DB, Guz A. Sites and sizes of fat deposits around the pharynx in obese patients with obstructive sleep apnoea and weight matched controls. Eur Respir J. 1989;2:613-22.

34. Spiegel K, Tasali E, Penev P, Van Cauter E. Brief communication: sleep curtailment in healthy young men is associated with decreased leptin levels, elevated ghrelin levels, and increased hunger and appetite. Ann Intern Med. 2004;141:846-50.

35. Copinschi G. Metabolic and endocrine effects of sleep deprivation. Essent Psychopharmacol. 2005;6:341-7.

36. Herder C, Peltonen M, Svensson PA, Carstensen M, Jacobson P, Roden M, Sjostrom L, Carlsson L. Adiponectin and bariatric surgery: associations with diabetes and cardiovascular disease in the Swedish obese subjects study. Diabetes Care. 2014;37:1401-9.

37. Rasmussen MH. Obesity, growth hormone and weight loss. Mol Cell Endocrinol. 2010;316:147-53. 
38. Dixon JB, Schachter LM, O'Brien PE. Predicting sleep apnea and excessive day sleepiness in the severely obese: indicators for polysomnography. Chest. 2003;123:1134-41.

39. Frey WC, Pilcher J. Obstructive sleep-related breathing disorders in patients evaluated for bariatric surgery. Obes Surg. 2003;13:676-83.

40. Cattano D, Sridhar S, Cai C, Mullaly A, Kainer L, Sparkle T, Castriotta RJ, Courtney S, Hagberg CA. Assessing risk of obstructive sleep apnea by STOP-BANG questionnaire in an adult surgical population screened in the preoperative anesthesia clinic. Minerva Anestesiol. 2015 [Epub ahead of print].

41. Holty JE, Parimi N, Ballesteros M, Blackwell T, Cirangle PT, Jossart GH, Kimbrough ND, Rose JM, Stone KL, Bravata DM. Does surgically induced weight loss improve daytime sleepiness? Obes Surg. 2011;21:1535-45.

42. Toor P, Kim K, Buffington CK. Sleep quality and duration before and after bariatric surgery. Obes Surg. 2012;22:890-5.

43. Maddi SR, Fox SR, Khoshaba DM, Harvey RH, Lu JL, Persico M. Reduction in psychopathology following bariatric surgery for morbid obesity. Obes Surg. 2001;11:680-5.

44. Kolotkin RL, Crosby RD, Gress RE, Hunt SC, Adams TD. Two-year changes in health-related quality of life in gastric bypass patients compared with severely obese controls. Surg Obes Relat Dis. 2009;5:250-6.

45. Rutledge T, Braden AL, Woods G, Herbst KL, Groesz LM, Savu M. Five-year changes in psychiatric treatment status and weight-related comorbidities following bariatric surgery in a veteran population. Obes Surg. 2012;22:1734-41.

46. Chou PS, Chang WC, Chou WP, Liu ME, Lai CL, Liu CK, Ku YC, Tsai SJ, Chou YH, Chang WP. Increased risk of benign prostate hyperplasia in sleep apnea patients: a nationwide population-based study. PLoS One. 2014;9:e93081.

47. Torre-Bouscoulet L, Garcia Sancho C, Vazquez Garcia JC, Salazar-Pena CM, Lopez Varela MV, de Oca MM, Muino A, Talamo C, Valdivia G, Menezes AM, Perez-Padilla R. Perceptions of short and long sleep duration and comorbid conditions: the PLATINO study. Sleep Med. 2013;14:850-7.

48. Vela MF, Kramer JR, Richardson PA, Dodge R, El-Serag HB. Poor sleep quality and obstructive sleep apnea in patients with GERD and Barrett's esophagus. Neurogastroenterol Motil. 2014;26:346-52.

49. Ng SS, Chan RS, Woo J, Chan TO, Cheung BH, Sea MM, To KW, Chan KK, Ngai J, Yip WH, Ko FW, Hui DS. A randomized controlled study to examine the effect of a lifestyle modification program in OSA. Chest. 2015;148:1193-203.

50. Maki-Nunes C, Toschi-Dias E, Cepeda FX, Rondon MU, Alves MJ, Fraga RF, Braga AM, Aguilar AM, Amaro AC, Drager LF, Lorenzi-Filho G, Negrao CE, Trombetta IC. Diet and exercise improve chemoreflex sensitivity in patients with metabolic syndrome and obstructive sleep apnea. Obesity (Silver Spring). 2015;23:1582-90. 